\title{
Schedule Performance Analysis of Infrastructure Reconstruction Projects Due to Extreme Events
}

\author{
Elnaz Safapour ${ }^{1}$, Sharareh Kermanshachi ${ }^{2}$ and Thahomina Jahan Nipa ${ }^{3}$
}

1 Department of Civil Engineering, University of Texas at Arlington, Arlington, USA, elnaz.safapour@mavs.uta.edu

2 Department of Civil Engineering, University of Texas at Arlington, Arlington, USA, sharareh.kermanshachi@uta.edu

3 Department of Civil Engineering, University of Texas at Arlington, Arlington, USA, thahomina.nipa@mavs.uta.edu

\begin{abstract}
Timely post-disaster reconstruction of transportation infrastructures is vital, as it affects the pace of the overall physical and economic recovery of the disaster-ravaged area. To ensure the completion of the project within the optimum amount of time, it is important to know what factors affect the duration of the project, but it is difficult to find a comprehensive list of those factors in the current literature. This study aims to fill that knowledge gap by identifying the factors that affect the timely reconstruction of transportation infrastructures (PRTs) following a natural disaster. A survey was developed and distributed to collect data for this study, and the responses were analyzed statistically. It was found that the possibility of schedule overruns increases with the levels of complexity and damage. Hurricanes in particular cause sudden shortages of resources (experts, suppliers, laborers, materials, and equipment) that reduce the productivity and increase the duration of reconstruction projects. The results of this study will help practitioners and engineers take steps to complete reconstruction projects within the estimated schedule.
\end{abstract}

(c) 2020 The Authors. Published by Budapest University of Technology and Economics \& Diamond Congress Ltd Peer-review under responsibility of the Scientific Committee of the Creative Construction Conference 2020.

Keywords: identification of factors, post-disaster reconstruction, reconstruction time, transportation infrastructure

\section{Introduction}

Transportation systems are key to public mobility, access, economy, safety, and the environment [1, 2] therefore, it is essential that they be returned to a safe and operational state within the shortest possible time and within a reasonable budget after a natural disaster [3,4]. For instance, critical highways were disrupted at four locations in the northwestern Los Angeles metropolitan area by the 1991 Northridge disaster [5], leading to substantial disruptions in the movement of people, and the closure of parts of Interstate 10 (Santa Monica Freeway) led to economic losses that were estimated at \$1 million per day [6]. After the disaster in Aceh and Nias [7], the damages to the transportation systems were responsible for $19.7 \%$ of the total estimated damages caused by the disaster. Similarly, in 2004, in Sri Lanka, losses and damages to roads and other parts of the transportation sector accounted for $22 \%$ of the total damages. These are only a few examples of the socioeconomic disruptions that communities experience until the transportation systems are restored to their pre-event condition.

Natural disasters, especially hurricanes, create shortages of resources such as laborers, equipment, and materials that make it difficult for reconstruction to be completed within the estimated time $[8,9,10,11]$ and the public reacts by exerting additional pressure on the local governments when the contractors are not able to deliver their services on time $[12,13,14]$. In addition, the complicated, hectic, and dynamic 
nature of transportation reconstruction exacerbates other problems and increases the likelihood of schedule overruns and reworks $[15,16]$. The dearth of research that addresses the issue of schedule overruns makes it difficult for practitioners to complete their projects on time [17].

Therefore, this study aims to identify the factors that affect post-disaster reconstruction time of transportation infrastructures (PRTs) to fill the abovementioned gap of knowledge in the literature. Several objectives were formulated to fulfill the goals of this study: i) identify the potential critical PRTs that affect the post-disaster reconstruction duration of transportation infrastructures, ii) categorize the identified PRTs, and iii) identify the most significant PRTs. The result of this study will help practitioners and engineers take the proper steps to complete their reconstruction projects within the initially estimated schedule.

\section{Literature review}

Hurricanes cause serious losses and damages that result in serious disruptions in the U.S. [18, 19]. Hurricane Katrina and Hurricane Rita led to tremendous socioeconomic damages. The accumulated direct and indirect economic losses and damages after Hurricane Katrina amounted to roughly $\$ 1845$ billion, while the primary estimation was $\$ 160$ billion [20]. The destruction caused physical and psychological distress to the victims, adversely impacted the environment, and rendered many of the critical infrastructures inoperable. Transportation systems are one of the infrastructures most severely affected by disasters $[21,22,23]$. The storm surges that accompany a hurricane affect the coastal areas, damaging many of the roads and depositing large amounts of debris, which can increase the cost and delay recovery activities for a prolonged period [24]. Following Hurricane Katrina, for example, economic loss for debris removal was approximately $\$ 200$ million [25]. Damaged transportation systems cause disruptions in traffic flows and slow the pace of overall recovery, resulting in more indirect than direct losses [26]. Thus, the reconstruction of transportation infrastructures is critical to the recovery of affected areas after any disaster [27].

In 1987 [28], Pinto and Slevin espoused that a project can be considered successful if it is completed on time, on budget, meets all its objectives, and satisfies the client. Various studies have been conducted on successful construction projects, using their definition [29, 30, 31, 32, 33, 34, 35]. Almost all researchers believe that staying within the budget, adhering to the schedule, and achieving a quality project performance, referred to as "the iron triangle" by Atkinson [36] is necessary for the success of a construction project $[37,38,39,40]$. Transportation agencies are experiencing unprecedented pressure to deliver projects on time and on budget, with an adequate level of quality $[41,42,43]$, and an obvious response to this pressure is to improve the project delivery process by adopting effective project management strategies $[44,45,46,47]$.

Every reconstruction project is unique in nature; hence it is difficult to determine the factors that will determine the success or failure of a project [48]. Similarly, it is difficult to determine the exact causes of schedule overruns in post-disaster reconstruction projects. Table 1 depicts the a few of the challenges that researchers have determined affect the success of post-disaster reconstruction projects by causing schedule overruns.

As shown in the table, Ika et al. [49] believed that ineffective designs are one of the main reasons for failing to complete a project within the estimated schedule. Delays in decision making during different stages of projects have also been attributed to delays that ultimately affect their success. The pace of recovery and the return of society to its norm is highly determined by the fastest possible recovery of the transportation infrastructures [50]. Hence, it is imperative that the reconstruction is completed with least possible schedule overruns [51]. Understanding and identifying the factors that will eliminate schedule overruns is absolutely necessary for this purpose [52], and this study aims to identify such factors. 
Table 1. Challenges affecting success and schedule of post-disaster reconstruction projects

\begin{tabular}{lc}
\hline Challenge & Previous Study \\
\hline Delays in delivering resources & {$[53,54]$} \\
Inappropriate assessment & {$[55]$} \\
Ineffective design & {$[49]$} \\
Temporary paths & {$[56]$} \\
Difficulties in damage evaluation & {$[57]$} \\
Low pace of decision-making & {$[58]$} \\
Number and quality of inspections & {$[59]$} \\
Inability to relocate functions & {$[60]$} \\
Permitting and consenting & {$[61]$}
\end{tabular}

\section{Research methodology}

\subsection{Framework}

The four-step methodology shown in Figure 1 was followed in this study. In the first step, a comprehensive literature review was performed. After rigorously screening the articles, 89 were shortlisted for thorough study, and a list of potential PRTs was developed. In the second step, a survey was developed, pilot tested, and distributed. In the following step, the survey responses were statistically tested to identify the significant PRTs, and the results were interpreted, employing the expertise of the authors.
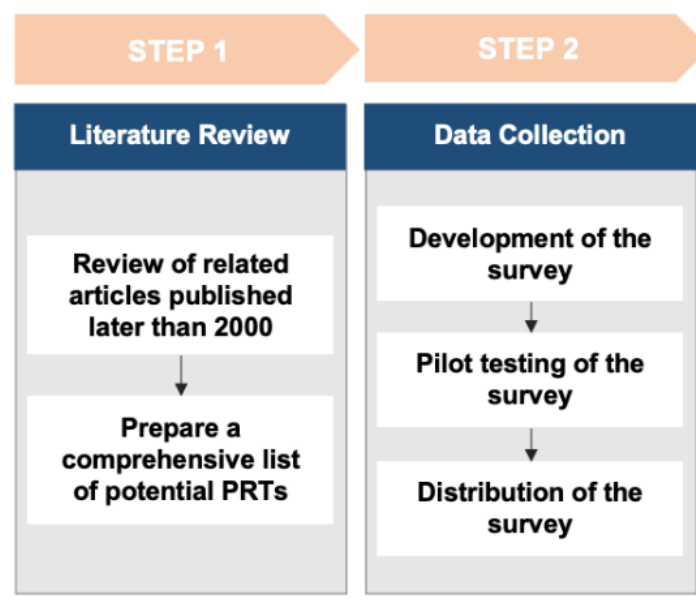
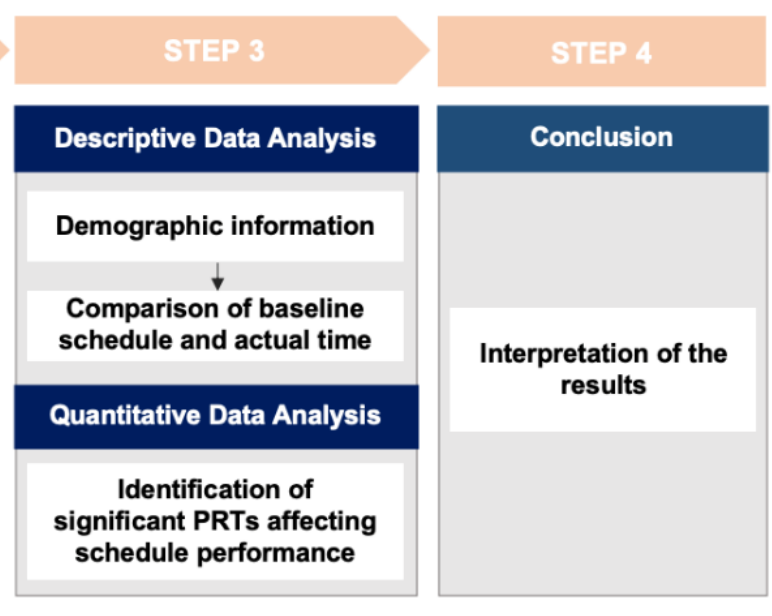

Fig. 1. Research methodology

\subsection{Statistical tests}

Three of the most popular and effective types of statistical tests were used for this study. The two-sample t-test was used for the continuous data that follows normal distribution, the Kruskal-Wallis was used for the seven-point Likert scale data that does not necessarily follow a normal distribution, and the Chi-squared test was used for the binary data of the survey questions that were answered by "yes" or "no." 


\section{Data collection}

\subsection{List of potential PRTs}

More than 200 relevant peer-reviewed journal articles, conference papers, dissertations, and research reports published on post-disaster reconstruction of transportation systems were collected for this study. Of those, over three-quarters of the articles were from journals because of the rigorousness of their review process. The research team established the following criteria for the articles that would be used: they must have been published in English after year 2000, they must be relevant to the post-disaster reconstruction of transportation systems, and they must be associated with engineering areas. After screening the articles, 89 of them were short-listed for thorough study. Short-listed articles were reviewed in depth to investigate the PRTs that significantly affect the cost and schedule performances, as well as the cost of reworks of posthurricane reconstruction of transportation infrastructures.

Two main steps were taken to identify the potentially significant PRTs: i) identify the potential PRTs that affect the schedule performance post-hurricane reconstruction of transportation infrastructures; and ii) determine which of the potential PRTs were cited the most often, retain them, and exclude the rest.

A list of 30 PRTs was developed of substantial factors for successful post-disaster reconstruction. They were classified into eight categories: general information, physical characteristics of the project, damage level, resources, environment and safety, project management, local, and legal.

Table 2. List of potential PRTs

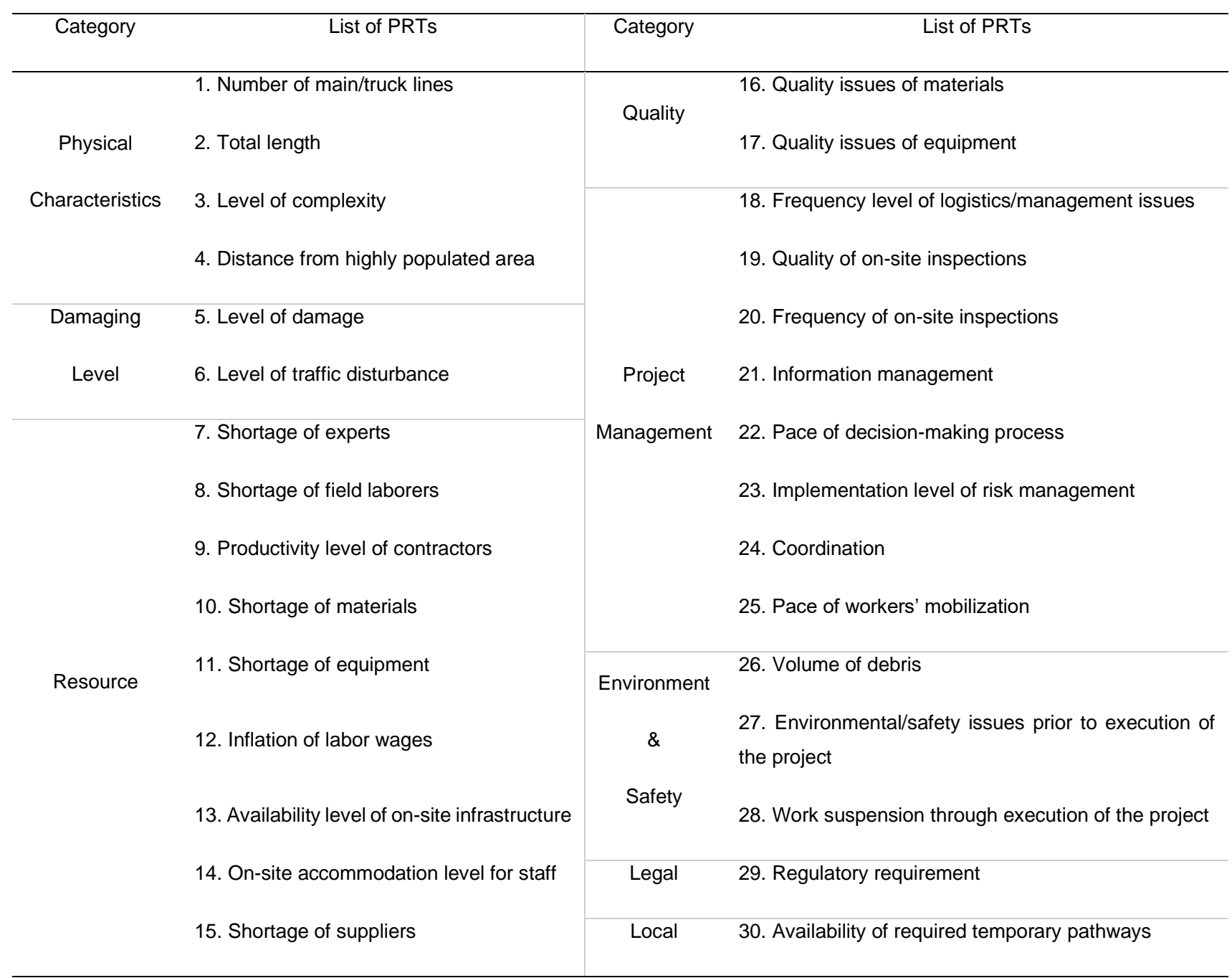




\subsection{Survey development and pilot testing}

A 46-question survey was developed, based on the potential list of PRTs (Table 2). It consisted of three types of questions, namely continuous, seven-point Likert scale, and binary. Questions regarding the respondents' demographic information were also included. Several of the questions from the survey are shown in Figure 2.

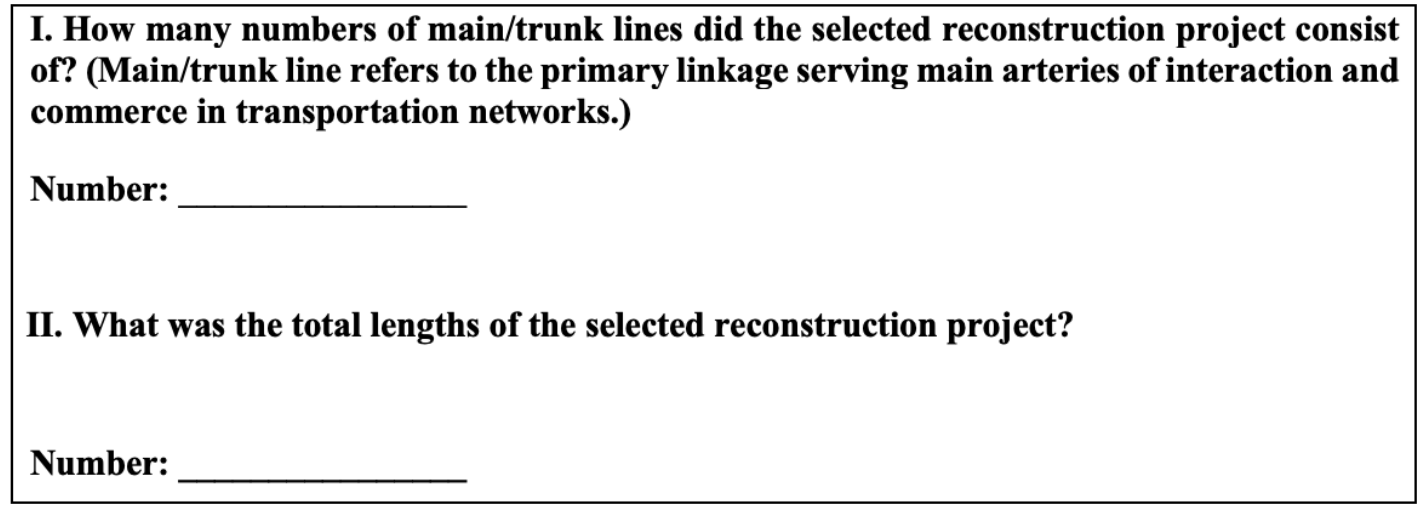

Fig. 2. Two sample questions of the survey

The survey was pilot tested and modified based on the responses.

\subsection{Survey distribution}

Specific criteria were established for those who would be invited to participate in the survey. One of them was that they must have experience in working on and/or monitoring the reconstruction of a transportation project. A list of potential participants was prepared and included program managers, directors, project managers, and engineers from different governmental and private agencies, state transportation agencies, and departments of transportation etc. They were contacted through email, and the surveys were distributed to them via electronic media after receiving a positive response. After multiple follow-up emails, 30 completed responses were collected.

\section{Descriptive analysis}

\subsection{Demographic information}

The demographic information of the survey respondents is presented in Table 3, which shows that about $70 \%$ of the respondents had more than 20 years of work experience, approximately $25 \%$ of them were program managers or directors, and the rest were project managers or engineers. All of the respondents were involved with the owner stakeholders.

Table 3. Demographic information of respondents

\begin{tabular}{cc|cc}
\hline Years of Experience & Percentage (\%) & Current Role in the Company & Percentage (\%) \\
\hline Less than 10 years & $12.5 \%$ & Program Manager & $8 \%$ \\
Between 10 and 20 years & $21 \%$ & Director & $17 \%$ \\
Between 21 and 30 years & $37.5 \%$ & Project Manager & $30 \%$ \\
More than 30 years & $29 \%$ & Engineer & $45 \%$ \\
\hline
\end{tabular}

\subsection{Comparison of projects' baseline schedules and actual time}

Box plots were used to demonstrate the baseline schedule and actual time of the selected reconstruction projects for which the respondents provided information, and the results are presented in Figure 3. It was observed that the maximum values of the projects' actual time and baseline schedules were about 90 
months and 60 months, respectively. The medians of actual time and baseline schedules were roughly 12 months and 20 months, respectively. Both of the results demonstrated the marked differences in the baseline schedules and the actual time of the selected reconstruction projects.

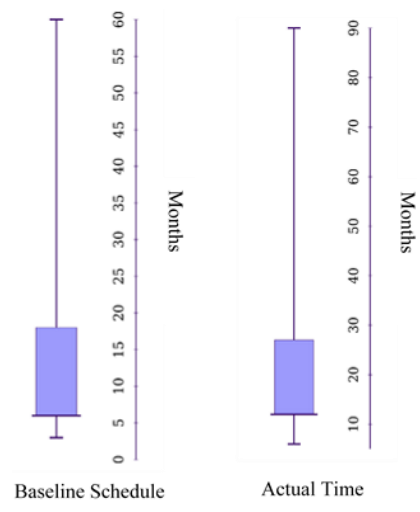

Fig. 3. Comparison of projects' baseline schedules and actual time

\section{Quantitative analysis}

\subsection{Identifying significant PRTs affecting projects'schedule performance}

The survey was constructed using three types of data: 1) continuous, 2) seven-point Likert scale, and 3) binary. Three types of statistical tests, the two-sample t-test, 2) Kruskal-Wallis test, and 3) Chi-squared test were used for the types of data, respectively. The P-values that identified the PRTs that most significantly affect the schedule performance of post-hurricane reconstruction of transportation infrastructures are presented in Table 4 and show that 20 out of 30 identified PRTs were statistically significant.

Table 4. Results of significant PRTs affecting reconstruction schedule

\begin{tabular}{|c|c|c|}
\hline Category & List of PRTs & $P$-Value \\
\hline & PRT1. Number of main/truck lines & $0.022^{\star \star}$ \\
\hline Physical & PRT2. Total length & 0.850 \\
\hline \multirow[t]{2}{*}{ Characteristics } & PRT3. Level of complexity & $0.042^{\star *}$ \\
\hline & PRT4. Distance from highly populated area & $0.078^{*}$ \\
\hline Damaging & PRT5. Level of damage & $0.011^{* *}$ \\
\hline \multirow[t]{5}{*}{ Level } & PRT6. Level of traffic disturbance & $0.061^{*}$ \\
\hline & PRT7. Shortage of experts & $0.011^{* *}$ \\
\hline & PRT8. Shortage of field laborers & $0.012^{\star *}$ \\
\hline & PRT9. Productivity level of contractors & $0.025^{\star *}$ \\
\hline & PRT10. Shortage of materials & $0.037^{\star *}$ \\
\hline \multicolumn{3}{|l|}{ Resource } \\
\hline & PRT11. Shortage of equipment & $0.017^{\star *}$ \\
\hline & PRT12. Inflation of labor wages & 0.290 \\
\hline & PRT13. Availability level of on-site infrastructure & 0.750 \\
\hline & PRT14. On-site accommodation level for staff & 0.410 \\
\hline
\end{tabular}




\begin{tabular}{|c|c|c|}
\hline & PRT15. Shortage of suppliers & $0.020^{* *}$ \\
\hline & PRT16. Quality issues of materials & $0.081^{*}$ \\
\hline \multicolumn{3}{|l|}{ Quality } \\
\hline & PRT17. Quality issues of equipment & $0.021^{\star \star}$ \\
\hline & PRT18. Frequency level of logistics/management issues & $0.013^{* *}$ \\
\hline & PRT19. Quality of on-site inspections & $0.032^{* *}$ \\
\hline & PRT20. Frequency of on-site inspections & 0.422 \\
\hline Project & PRT21. Information management & $0.068^{*}$ \\
\hline \multirow[t]{4}{*}{ Management } & PRT22. Pace of decision-making process & $0.041^{* *}$ \\
\hline & PRT23. Implementation level of risk management & $0.082^{*}$ \\
\hline & PRT24. Coordination & $0.046^{\star *}$ \\
\hline & PRT25. Pace of workers' mobilization & 0.258 \\
\hline Environment & PRT26. Volume of debris & 0.124 \\
\hline \& & PRT27. Environmental/safety issues prior to execution of the project & 0.274 \\
\hline Safety & PRT28. Work suspension through execution of the project & $0.001^{* *}$ \\
\hline Legal & PRT29. Regulatory requirement & 0.205 \\
\hline Local & PRT30. Availability of required temporary pathways & 0.163 \\
\hline
\end{tabular}

\subsection{Interpretation of the results}

The physical characteristics of a project have a significant impact on the project schedule. Table 4 shows that three PRTs, namely PRT-1 (high number of main lines), PRT-3 (level of complexity), and PRT-4 (distance from highly populated area) have significant $p$-values because they often result in complex plans and schedules. In addition, their presence might increase the number of discussions between the stakeholders and cause delays.

The level of damage also affects the reconstruction project schedule appreciably. For instance, a highway or bridge with a high level of damage creates a major traffic disturbance, and the delays that are inherent in providing a temporary route for the disrupted traffic frequently cause delays that translate into schedule overruns for the project.

A lack of resources is one of the major causes of the failure of transportation reconstruction projects. Table 4 illustrates that shortages of experts, laborers, materials, equipment, and suppliers affect the reconstruction schedule. The contractors' level of productivity is also a major factor in whether a project will be completed on time, as all reconstruction projects after natural disasters are complicated, unexpected, and need a quick turnaround.

Quality is another important category in controlling the schedule of reconstruction projects, and unexpected issues with the quality of materials (PRT16) and/or equipment (PRT17) can cause delays. 
The time and budget constraints of reconstruction projects require that they be efficiently managed. Ineffective coordination (PRT-24) means lack of alignment among project organizations and/or team members. The process of communication can be time-consuming and affect the schedule performance.

The environment and safety, legal, and local categories have less impact on the duration of reconstruction projects of transportation infrastructures, but if the work has to be suspended because of issues related to any of these categories, it negatively impacts the schedule of the project.

\section{Conclusion}

Transportation infrastructures are highly affected by natural disasters, especially by hurricanes, and the recovery pace of the affected community depends largely on their reconstruction. For this reason, it is necessary to ensure the completion of the reconstruction of transportation infrastructures after a disaster within the estimated time and budget. Unfortunately, it is not rare for such projects to be prolonged for various reasons, which adversely affects the overall recovery of the community. The existing literature lacks lists of significant factors that affect the reconstruction schedule of transportation infrastructures after natural disasters; therefore, the aim of this study was to identify those critical factors To this end, a survey was developed and distributed to a select group of experts, and after the 30 responses were collected and statistically analysed, it was found that the possibility of schedule overruns increases with an increase in the complexity and damage levels of the projects. The shortages of resources (experts, suppliers, laborers, materials, and equipment) that accompany a hurricane reduce productivity and increase the estimated time of completion. The result of this study will help practitioners and engineers take the steps that are necessary to complete reconstruction projects within the estimated schedule.

\section{References}

[1] J. Mallela, S. Sadasivam. "Work zone road user costs- Concepts and applications". Federal Highway Administration, U.S. Dept. of Transportation, Washington, DC, 2011.

[2] Kermanshachi S, Beaty C, Anderson S D. "Improving Early phase cost estimation and risk assessment: A department of transportation case study. 95 $5^{\text {th }}$ Annual Meeting of the Transportation Research Board (TRB), 2016.

[3] Kermanshachi, S.; Bergstrand, K.; Rouhanizadeh, B. "Identifying, weighting and causality modeling of social and economic barriers to rapid infrastructure recovery from natural disasters: A study of hurricanes Harvey, Irma and Maria". Technical report, 2019.

[4] Safapour E, Kermanshachi S, Nipa T J. Analysis of Cost Performance Indicators in Reconstruction Projects: A Comparative Study of Low Vs. High Level Damages. Creative Construction Conference (CCC), 2020

[5] S.E. Chang, N. Nojima. "Measuring post-disaster transportation system performance: the 1995 Kobe earthquake in comparative perspective". Transportation Research Part A: Policy and Practice, 2001, 35(6), 475-494, 2001. https://doi.org/10.1016/S09658564(00)00003-3

[6] N. Zamichow, V. Ellis. "Santa Monica freeway to reopen on Tuesday recovery: The contractor will get a \$14.5-million bonus for finishing earthquake repairs 74 days early." Los Angeles Times, 1994.

[7] Bappenas and the International Donor Community (eds.). "Indonesia: Notes on reconstruction-the December 26, 2004 natural disaster, Jakarta, 19 January," BAPPENAS, Blue print for the reconstruction of Aceh and Nias, March 2005.

[8] B. Hidayat, C. Egbu. "A literature review of the role of project management in post-disaster reconstruction," Proceedings of $26^{\text {th }}$ Annual ARCOM Conference, Association of Researchers in Construction Management, Leeds, 2010.

[9] Y. Chang, S. Wilkinson, D. Brunsdon. "An integrated approach: managing resources for post-disaster reconstruction". Disasters, 35(4), 739-65, 2011. https://doi.org/10.1111/j.1467-7717.2011.01240.x

[10] Pamidimukkala A, Kermanshachi S, Kartick S. "Impact of Natural Disasters on Construction Projects: Strategies to Prevent Cost and Schedule Overruns in Reconstruction projects". Creative Construction Conference (CCC), 2020.

[11] Safapour, E.; Kermanshachi, S. "Identification and categorization of factors affecting duration of post-disaster reconstruction of interdependent transportation systems". ASCE Construction Research Congress (CRC), 2019.

[12] Rouhanizadeh, B.; Kermanshachi, S. "A Systematic Approach to Analysis and Prioritization of the Socioeconomic Policies and Legal barriers to Rapid Post Disaster Reconstruction". 7th CSCE International Construction Specialty Conference (ICSC), 2019

[13] Rouhanizadeh, B.; Kermanshachi, S. "Comparative analysis of public's and decision-maker's perspectives on socioeconomic barriers causing delay in post-disaster recovery processes". ASCE Construction Research Congress (CRC), 2019.

[14] Rouhanizadeh, B.; Kermanshachi, S.; Dhamangaonkar, V. "Identification and categorization of policy and legal barriers to long-term timely post-disaster reconstruction". Journal of Legal Affairs and Dispute Resolution in Engineering and Construction, Volume 11 issue 3, 2019. https://doi.org/10.1061/(asce)la.1943-4170.0000307

[15] A.K. Jha, J.E. Duyne. "safer homes, stronger communities: a handbook for reconstructing after natural disasters". World Bank Publications, 2010. https://doi.org/10.1596/978-0-8213-8045-1

[16] Safapour, E., Kermanshachi, S., Nipa, T.J. "A Damage-based Analysis of Rework in Reconstruction of Infrastructure Projects Due to Natural Disasters". Creative Construction Conference (CCC), 2020.

[17] Kermanshachi, s. "Decision making and uncertainity analysis in success of construction projects". Ph.D. Dissertation, Texas A \& M University, 2016.

[18] M.W. Horner, J. A. Downs. "Optimizing hurricane disaster relief goods distribution: model development and application with respect to planning strategies". Disasters, 34(3), 821-844, 2010. https://doi.org/10.1111/j.1467-7717.2010.01171.x

[19] Rouhanizadeh, B.; Kermanshachi, S.; Dhamangaonkar, V. "Reconstruction of critical and interdependent infrastructures due to catastrophic natural disasters: lessons learned". ASCE Construction Research Congress, 2019.

[20] R.D. Knabb, J.R. Rhome, D.P. Brown. "Tropical cyclone report, Hurricane Katrina, 23-30 August 2005”. National Hurricane Center, Miami, 2006. 
Proceedings of the Creative Construction e-Conference (2020) 064

Available online at e-2020.creative-construction-conference.com/proceedings/

[21] E. Hayat, R.D.G. Amaratunga. "Road reconstruction in post-disaster recovery; the challenges and obstacles". In: International Conference on Building resielience, 2011.

[22] Nipa T, J., Kermanshachi, S. Identification of the Resilience Dimensions and Determination of their Relationships in Critical Transportation Infrastructures. ASCE Construction Research Congress (CRC), 2019

[23] Nipa T, J., Kermanshachi, S., Ramaji I, J. Comparative analysis of strengths and limitations of infrastructure resilience measurement methods. $7^{\text {th }}$ CSCE International Construction Speciality Conference (ICSC), 2019

[24] Rouhanizadeh, B.; Kermanshachi, S.; Nipa, T. J. "Identification, categorization, and weighting of barriers to timely post-disaster recovery process". ASCE International Conference on Computing in Civil Engineering, 2019. https://doi.org/10.1061/9780784482445.006

[25] J. Padgett, R. Des Roches, B. Nielson, M. Yashinsky, O.S. Kwon, N. Burdette, E. Tavera, E. "Bridge damage and repair costs from Hurricane Katrina". Journal of Bridge Engineering, 13(1), pp.6-14, 2008. https://doi.org/10.1061/(ASCE)1084-0702(2008)13:1(6)

[26] A. Rose, D. Wei, A. Wein. "Economic impacts of the ShakeOut scenario". Earthquake Spectra, 27(2), 539-557, 2011. https://doi.org/10.1193/1.3587204

[27] Rouhanizadeh, B., \& Kermanshachi, S. "Investigating the Relationships of Socioeconomic Factors Delaying Post-Disaster Reconstruction". In Proceedings of ASCE International Conference on Computing in Civil Engineering, pp. 17-19. 2019. https://doi.org/10.1061/9780784482445.005

[28] J. K. Pinto, D. P. Slevin. “Critical factors in successful project implementation”. IEEE Trans. Eng. Manage., 34(1), $22-27,1987$. https://doi.org/10.1109/tem.1987.6498856

[29] P. Nixon, M. Harrington, D. Parker. "Leadership performance is significant to project success or failure: a critical analysis". International Journal of Productivity and Performance Management 61(2), 2012. https://doi.org/10.1108/17410401211194699

[30] M.M.D. Carvalho, R. Rabechini Junior. "Impact of risk management on project performance: the importance of soft skills". International Journal of Production Research, 53(2), pp.321-340, 2015. https://doi.org/10.1080/00207543.2014.919423

[31] K. Davis. "A method to measure success dimensions relating to individual stakeholder group". International Journal of Project Management, 34(3), pp.480-493, 2016. https://doi.org/10.1016/j.ijproman.2015.12.009

[32] L. Wang, M. Kunc, S.J. Bai. "Realizing value from project implementation under uncertainty: An exploratory study using system dynamics". International Journal of Project Management, 35(3), pp.341-352, 2017. https://doi.org/10.1016/j.ijproman.2017.01.009

[33] Kermanshachi S, Dao B, Shane J, Anderson S." Uncertainty analysis of procurement phase performance indicators using extreme bounds analysis (EBA)". In proceedings of the 6th CSCE International Construction Specialty Conference, 2017.

[34] Habibi M, Kermanshachi S, Safapour E. "Engineering, procurement and construction cost and schedule performance leading indicators: state-of-the-art review". ASCE Construction Research Congress (CRC), 2018. https://doi.org/10.1061/9780784481271.037

[35] Habibi M, Kermanshachi S. "Phase-based analysis of key cost and schedule performance causes and preventive strategies". Engineering, Construction and Architectural Management 25(8), 2018. https://doi.org/10.1108/ecam-10-2017-0219

[36] R. Atkinson, "Project management: Cost, time and quality, two best guesses and a phenomenon, its time to accept other success criteria". International Journal of Project Management, 17(6), 337-342, 1999. https://doi.org/10.1016/S0263-7863(98)00069-6

[37] S. K. Viswanathan, K.K. Tripathi, K.N. Jha. "Influence of risk mitigation measures on international construction project success criteria-a survey of Indian experiences". Construction Management and Economics, pp 1-16, 2019. https://doi.org/10.1080/01446193.2019.1577987

[38] S. Narayan, H.C. Tan. "Adopting big data to forecast success of construction projects: A Review". Malaysian Construction Research Journal, 6(1), 132-143, 2019.

[39] S.K. Silva, B.N.F. Warnakulasuriya, B.J.H. Arachchige. "A Scale for measuring perceived construction project success-Sri Lankan Perspective". Studies in Business and Economics, 14(1), pp 245-258, 2019. https://doi.org/10.2478/sbe-2019-0019

[40] Kermanshachi S, Zheng Y, Anderson S D, Cliff S, Molenaar K R. "Cost Estimating Tool for Early Estimates for Rural and Small Urban Transit Facilities". 95 ${ }^{\text {th }}$ Annual Meeting of Transportation Research Board (TRB), 2016.

[41] P.E. Love, M.C. Sing, L.A. Ika, S. Newton, S. "The cost performance of transportation projects: The fallacy of the Planning Fallacy account". Transportation Research Part A: Policy and Practice, 122, pp 1-20, 2019. https://doi.org/10.1016/j.tra.2019.02.004

[42] Safapour E, Kermanshachi S, Alfasi B, Akhavian R. "Identification of Schedule-Performance Indicators and Delay-Recovery Strategies for Low-Cost Housing Projects". Sustainability 11(21), 2019. https://doi.org/10.3390/su11216005

[43] Habibi M, Kermanshachi S, Rouhanizadeh B. "Identifying and Measuring Engineering, Procurement, and Construction (EPC) Key Performance Indicators and Management Strategies". Infrastructures 4(14), 2019. https://doi.org/10.3390/infrastructures4020014

[44] S.K. Silva, B.N.F. Warnakulasuriya, B.J.H. Arachchige. "A Scale for measuring perceived construction project success-Sri Lankan Perspective". Studies in Business and Economics, 14(1), pp 245-258, 2019. https://doi.org/10.2478/sbe-2019-0019

[45] Kermanshachi S. "US multi-party standard partnering contract for integrated project delivery”. Master Dissertation, Mississippi state university, 2010

[46] Arash T, Jafari A, Kermanshachi S." Exploring Project Management Practices in the US Transportation Agencies". ASCE Construction Research Congress (CRC), 2019.

[47] Safapour E, Kermanshachi S, Jafari A. "Effective Project Management Principles and Strategies in Transportation Infrastructure Projects". Creative Construction Conference (CCC), 2020

[48] Safapour E, Kermanshachi S, Shane J, Anderson S. "Exploring and assessing the utilization of best practices for achieving excellence in construction projects". In proceedings of the 6th CSCE International Construction Specialty Conference, 2017.

[49] L. A. Ika, A. Diallo, A., D. Thuillier. "Critical success factors for World Bank projects: An empirical investigation". International Journal of Project Management, 30(1), 105-116, 2012. https://doi.org/10.1016/j.ijproman.2011.03.005

[50] D.M. Frangopol, P. Bocchini. "Resilience as optimization criterion for the rehabilitation of bridges belonging to a transportation network subject To earthquake". In Structures Congress 2011, pp. 2044-2055, 2011. https://doi.org/10.1061/41171(401)178

[51] Kermanshachi, S., \& Rouhanizadeh, B. "Feasibility analysis of post disaster reconstruction alternatives using automated BIM-based construction cost estimation tool". In Proceeding of CSCE 6th International Disaster Mitigation Specialty Conference, Montreal: Canadian Society of Civil Engineering, pp. 13-16. 2018.

[52] Pamidimukkala A, Kermanshachi S, Safapour E. Challenges in Post-Disaster Housing Reconstruction: Analysis of Urban Vs. Rural Communities". Creative Construction Conference (CCC), 2020

[53] T. Iwai, S. Tabuchi. "Survey: Housing projects delayed for more than 10,000 evacuees". The Asahi Shimbun, 2013

[54] A. Moloney. "Haitians still homeless "suffering in despair" 4 years after quake - Amnesty". Thomson Reuters Foundation, 4-6, 2014.

[55] J. Kennedy, J. Ashmore, E. Babister, I. Kelman. "The meaning of "build back better: evidence from post-tsunami Aceh and Sri Lanka". Journal of Contingencies and Crisis Management, 16(1), 24-36, 2008. https://doi.org/10.1111/j.1468-5973.2008.00529.x

[56] M.A. Choudhary, K. Mehmood. "Causes of success and failure of post disaster reconstruction projects-A case study of post 2005 earthquakes in Northern Pakistan”. Planet@Risk, 1(1), 2013.

[57] D. Brunsdon, J. Hare, M. Stannard. "The impact of the Canterbury earthquake sequence on the engineering profession in New Zealand". Paper presented at the Australian Earthquake Engineering Society 2012 Conference, December 7-9, Gold Coast. https://doi.org/10.5459/bnzsee.46.1.56-67 
Proceedings of the Creative Construction e-Conference (2020) 064

Available online at e-2020.creative-construction-conference.com/proceedings/

[58] F. Marquis, J.J. Kim, K.J. Elwood, S.E. Chang. "Understanding post-earthquake decisions on multi-storey concrete buildings in Christchurch, New Zealand". Bulletin of Earthquake Engineering, 15(2), 731-758, 2017. https://doi.org/10.1007/s10518-015-9772-8

[59] I. Almufti, M. Willford, "REDi ${ }^{\mathrm{TM}}$ rating system: Resilience-based earthquake design initiative for the next generation of buildings". Project, 2013. https://doi.org/10.13140/RG.2.2.2067.75043

[60] M.C. Comerio. "Estimating downtime in loss modeling". Earthquake Spectra, 22(2), 349-365, 2006. https://doi.org/10.1193/1.2191017

[61] A. Chang-Richards, C. Brown, N. Smith. "A system dynamics model of post-earthquake reconstruction pathways". Centre for earthquake resilience, 2017. 